\title{
STAND DENSITY INDICES FOR FOREST PLANTATIONS
}

\author{
T Sivananthawerl \\ Department of Crop Science, Faculty of Agriculture, \\ University of Peradeniya, Perdeniya
}

Stand density can be defined as the quantitative measure of stocking expressed either absolutely in terms of number of trees, basal area, or volume per unit area or relative to some stand condition. It is an important measure to schedule thinning regimes especially in the even-aged stands. There are a number of indices available to quantify the stand density. However, matching density indices are mostly depends on species and its growth behaviour. In this study four different stand density indices were compared on Eucalyptus grandis stands grown in the Nuwara-Eliya division.

The first index is the basal area, which is a conventional method to measure stand density. In managed plantations due to the lack of continuity, it is not so widely used among the even aged stands, though it is the major tool to measure the density in natural forests. The maximum observed basal area was $74.6 \mathrm{~m}^{2} / \mathrm{h}$ a and the minimum was $3.6 \mathrm{~m}^{2} / \mathrm{ha}$. The second index is the relative spacing (RS). Plantations are more suitable to indicate their stand density by measuring relative spacing. The minimum observed relative spacing was 0.088 and the maximum was 0.458.The third index Crown Competition Factor (CCF), describes the relationship between crown surface area and the stand area. This can be interpreted; as when the crown surface area for a unit land area is high then the stand density is high. It is a good measure to interpret the stand density situation for a dense crown species. The fourth popular stand density measure is Stand Density Index (SDI). Under the proper management system, it produces a basal area of $75 \mathrm{~m}^{2} / \mathrm{ha}$ with $195 \mathrm{stems} / \mathrm{ha}$ and mean diameter of $70 \mathrm{~cm}$.

There is no unique density index available for a particular tree species. The suitability of density indices depends not only on species but also on their growth behaviour. In this study, crown competition factor showed very less accessibility especially for $E$. grandis. Stand basal area is more descriptive and regardless of age, for the comparison of stands, it is inferior. Relative spacing is more appropriate for the stands where no thinning takes place. This explains how the number of stems/ha affects the RS with the age. This method is good to use in the spacing trial rather than to quantify the thinning. Stand density index (SDI) appeared to be the most prolific density index for this species. 